\title{
MOLECULAR DETECTION AND ANTIBIOGRAM OF SHIGA TOXIN PRODUCING ESCHERICHIA COLI (STEC) ISOLATED FROM DIARRHEIC CHILDREN
}

\author{
M. M. Islam, S. Ahamed, M. Y. Arafat, I. Hasan, M. Rahman and K. H. M. N. H. Nazir*
}

Department of Microbiology and Hygiene, Bangladesh Agricultural University, Mymensingh-2202, Bangladesh

\begin{abstract}
This study was designed to determine the shiga toxin producing genes and to investigate antibiotic sensitivity or resistant patterns of the Escherichia coli isolated from diarrheic children at Mymensingh Medical College Hospital, Bangladesh. A total of 83 stool samples were collected and screened for the detection of E. coli on the basis of cultural, staining and biochemical properties followed by molecular detection by Polymerase Chain Reaction (PCR) using genus specific 16SrRNA primers. Antimicrobial susceptibility pattern of $E$. coli was determined by disc diffusion method against 9 antimicrobial agents. In this study, 27 (32.53\%) out of 83 samples, were confirmed as E. coli. Overall prevalence of shiga toxin producing E. coli (STEC) among the examined children was $1.20 \%(\mathrm{n}=1 / 83)$. Further, $27 \mathrm{E}$. coli isolates were analyzed for the presence of Stx-1 and Stx-2 genes by duplex-PCR. The STEC isolate was confirmed to be positive for the presence of the Stx-2 gene only. Highest susceptibility of the E. coli isolates was found against Gentamicin (92.59\%), followed by Ciprofloxacin (48.14\%) and Moxifloxacin (33.33\%). More than $77.78 \%$ of the isolates were resistant to more than three antibiotics thus defined as multidrug resistant (MDR). In conclusion, Gentamicin and Ciprofloxacin can be recommended as the effective drugs successful treatment of STEC infections in children.
\end{abstract}

Key words: STEC, children, PCR, Antibiotic sensitivity, duplex PCR, Bangladesh

\section{INTRODUCTION}

Shiga toxin producing Escherichia coli (STEC) is known as Verotoxin producing E. coli. Infections due to STEC that can result in severe bloody diarrhea (hemorrhagic colitis, HC) which may evolve towards the lifethreatening hemolytic-uremic syndrome (HUS). Currently six E. coli pathotypes are recognized which can cause diarrhea in humans (Turner et al., 2006). Few studies have provided required information on the outbreak of disease producing or pathogenic E. coli (Higgins et al., 2005).

It is estimated that the diarrheal diseases account for $4.1 \%$ of the total daily global burden of diseases and are cause for the deaths of 1.8 million people every year and $90 \%$ of them are children under the age of 5 years of old (Islam et al., 2006). In addition, diarrheal illnesses responsible for an estimated 12,600 deaths each day in children under 5 years of old in Asia, Africa, and Latin America, especially in developing countries (Alikhani $e t$ al., 2006). STEC has become a major public health problem for the last few decades. Other strains may cause outbreaks including many waterborne diseases (Leelaporn et al., 2003). Sporadic cases and outbreaks have been already reported from many developed countries. STEC infections also have been reported in Latin America, India and some other developing countries (Kaddu-Mulindw et al., 2001; Leelaporn et al., 2003).

Though STEC has not been established as a major etiological agent of diarrhea in Bangladesh, it has already isolated from diarrheic children, cattle and calves; suggesting that this enteropathogen may cause a serious public health problem (Nazir et al., 2005, 2007; Islam et al., 2006; Munshi et al., 2012; Talukdar et al., 2013). STEC has also been reported from the broiler chicken in Bangladesh (Mamun et al., 2016). Several studies also showed isolation of shigatoxigenic E. coli from water (Talukdar et al., 2013) and from urine of the hospitalized patient in Bangladesh (Islam et al., 2015).

As per previous reports, it is revealed that several works have been performed for the isolation, identification and molecular characterization of STEC in Bangladesh (Islam et al., 2006; Ansari et al., 2014; Mamun et al., 2016; Jahan et al., 2016). However, most of the study patterns were based on surveillance system (Islam et al., 2006). Some studies showed isolation of E. coli on the basis of biochemical characterization only (Zinnah et al., 2007). Ahmed et al. (2012) studied with STEC considering both adult and children but not with hospitalized children. The present study was designed to isolate and identify E. coli from hospitalized diarrheic children, to detect the presence of virulent gene in the isolated $E$. coli, to determine the prevalence of $E$. coli in hospitalized diarrheic children and to determine the antibiotic sensitivity and resistance pattern of the isolated E. coli.

*Corresponding e-mail address: nazir@bau.edu.bd

Copyright (c) 2016 Bangladesh Society for Veterinary Medicine

All rights reserved 0389/2016 


\section{MATERIALS AND METHODS}

\section{Sample collection}

The research work was conducted during the period from January 2016 to May 2016 at the Department of Microbiology and Hygiene, Faculty of Veterinary Science (FVS), Bangladesh Agricultural University (BAU), Mymensingh-2202, Bangladesh. Samples of diarrheic stool of the affected hospitalized children were usually available at the Mymensingh Medical College Hospital (MMCH), Mymensingh. A cross-sectional study was designed to investigate the prevalence of the E. coli including STEC in diarrhea affected children at MMCH. A total number of 83 stool samples were collected by sterile cotton bud and were put into eppendorf tube containing nutrient broth and brought to the laboratory at the Department of Microbiology and hygiene, BAU by maintaining cool chain. Ages of the children were also recorded.

\section{Study design}

The whole experiment was divided into three steps. The steps included isolation of the bacteria from fecal samples of the hospitalized diarrheic children from MMCH. Identification of the E. coli by cultural, morphological, biochemical characteristics and PCR. Molecular characterization of STEC by duplex PCR followed by antibiotic sensitivity at the final step.

\section{Cultural identification}

Primary growth was performed in nutrient broth followed by inoculation into selective media and incubated at $37^{0} \mathrm{C}$ for overnight. After primary culture of the organism, a 10-fold dilution was made to reduce overgrowth of the organisms. After that $100 \mu \mathrm{l}$ was inoculated onto Mac-Conkey agar. The colonies showing typical cultural characteristics of $E$. coli were selected for subculture on selective media such as Eosin Methylene Blue (EMB). The colonies showing typical characteristics of E. coli onto EMB agar to confirm the isolates as E. coli. Gram's staining and a series of biochemical tests were also performed.

\section{Method of extraction of genomic DNA by boiling method}

The genomic DNA of each E. coli isolate was extracted by boiling method. Single colony of each isolate was inoculated into $200 \mu \mathrm{l}$ of distilled water followed by boiling for $10 \mathrm{~min}$. After boiling the samples were immediately kept on ice for few minutes for cold shock. Finally centrifugation was done at $10000 \mathrm{rpm}$ for 10 min. The supernatant was collected and used as DNA template for PCR.

\section{Amplification of 16SrRNA and Stx-1 and Stx-2 genes in E. coli by PCR}

To amplify 16SrRNA of $E$. coli genus specific primers were used (Table 1). The total volume of PCR mixture was $25 \mu$ l consisting of $12.5 \mu$ l PCR master mixture, $1 \mu 1$ of each primers, $5 \mu 1$ of template DNA. The thermal profile of PCR for $16 \mathrm{SrRNA}$ was $95^{\circ} \mathrm{C}, 5 \mathrm{~min}$ for initial denaturation, $94^{\circ} \mathrm{C}, 30 \mathrm{sec}$ for denaturation, $58^{\circ} \mathrm{C}, 1 \mathrm{~min}$ for annealing, $72^{\circ} \mathrm{C}, 1 \mathrm{~min}$ for elongation and $72^{\circ} \mathrm{C}, 10 \mathrm{~min}$ for final extension and the holding temperature was $4^{0} \mathrm{C}$. The thermal profile of PCR for Stx-1 and Stx -2 were $95^{\circ} \mathrm{C}, 5 \mathrm{~min}$ for initial denaturation, $94^{\circ} \mathrm{C}, 30 \mathrm{sec}$ for denaturation, $56^{\circ} \mathrm{C}, 1 \mathrm{~min}$ for annealing, $72^{\circ} \mathrm{C}, 1 \mathrm{~min}$ for elongation and $72^{\circ} \mathrm{C}, 10 \mathrm{~min}$ for final extension and the holding temperature was $4^{0} \mathrm{C}$.

Table 1. Primers used in this study with sequences

\begin{tabular}{|c|c|c|c|c|}
\hline Primer Name & $\begin{array}{c}\text { Gene } \\
\text { Targeted }\end{array}$ & Primer Sequence $\left(5^{\prime}-3^{\prime}\right)$ & $\begin{array}{l}\text { Amplicon } \\
\text { size (bp) }\end{array}$ & Reference \\
\hline EC16SrRNA F & & 5'GACCTCGGTTTAGTTCACAGA3' & \multirow[t]{2}{*}{585} & \multirow{2}{*}{$\begin{array}{c}\text { Schippa et al. } \\
\text { (2010) }\end{array}$} \\
\hline $\begin{array}{l}\text { EC16SrRNA } \\
\text { R }\end{array}$ & 16SrRNA & 5'CACACGCTGACGCTGACCA3' & & \\
\hline EC Stx-1 F & & 5'CACAATCAGGCGTCGCCAGCGCACTTGCT3' & \multirow[t]{2}{*}{606} & \multirow{2}{*}{$\begin{array}{c}\text { Heuvelink et al. } \\
\text { (1995) }\end{array}$} \\
\hline EC Stx-1R & Stx-1 & 5'TGTTGCAGGGATCAGTCGTACGGGGATGC3' & & \\
\hline EC Stx-2 F & & 5’CCACATCGGTGTCTGTTATTAACCACACC3' & \multirow[t]{2}{*}{372} & \multirow{2}{*}{$\begin{array}{l}\text { Heuvelink et al } \\
\text { (1995) }\end{array}$} \\
\hline EC Stx-2R & Stx-2 & 5'GCAGAACTGCTCTGGATGCATCTCTGGTC3' & & \\
\hline
\end{tabular}

$\mathrm{F}=$ Forward; $\mathrm{R}=$ Reverse; $\mathrm{bp}=$ Base pair 


\section{Antibiotic sensitivity test by the disc diffusion method}

The disc diffusion method was used to detect antimicrobial susceptibility assay according to the recommendation of Clinical and Laboratory Standards Institute (CLSI) (formerly National Committee for Clinical Laboratory Standards (CLSI, 2013). Susceptibility of E. coli isolates to 9 mostly prescribed antimicrobial agents (Table 3) were measured in vitro by employing the modified Kirby-Bauer method (Bauer et al., 1966).

\section{RESULTS AND DISCUSSION}

Initially, the $E$. coli were screened on the basis of characteristics colony morphologies on Mac-Conkey agar. Out of 83, 27 samples were suspected as E. coli based on fermentation of lactose on Mac-Conkey agar and development of bright pink or red colonies (Table 2). Each sample was then sub-cultured onto EMB agar. All 27 suspected E. coli isolates produced greenish-black colonies with metallic sheen on EMB agar. The pure cultures of suspected E. coli isolates were subjected for Gram staining. In Gram's staining method, the organisms were found as Gram-negative, small rod shaped, arranged in single or paired. In sugar fermentation tests, all the isolates produced both acid and gas by fermentation of sugars indicated by color change and deposition of gas in Durham's tube.

Table 2. Cultural characteristics and overall prevalence of 16SrRNA, Stx-2 gene

\begin{tabular}{ccccccccc}
\hline $\begin{array}{c}\text { Source } \\
\text { of } \\
\text { samples }\end{array}$ & $\begin{array}{c}\text { No. of } \\
\text { total } \\
\text { samples }\end{array}$ & $\begin{array}{c}\text { No. of } \\
\text { positive } \\
\text { samples }\end{array}$ & $\begin{array}{c}\text { No. of 16SrRNA } \\
\text { Positive } \\
\text { samples }\end{array}$ & $\begin{array}{c}\text { Stx-1 } \\
\text { Positive }\end{array}$ & $\begin{array}{c}\text { Stx-2 } \\
\text { Positive }\end{array}$ & $\begin{array}{c}\text { No. (\%) of } \\
\text { 16SrRNA }\end{array}$ & $\begin{array}{c}\text { No. (\%) of } \\
\text { Stx-1 }\end{array}$ & $\begin{array}{c}\text { No. (\%) of STEC } \\
\text { among No. (\%) of Stx- } \\
\text { sampled } \\
\text { patients }\end{array}$ \\
\hline MMCH & 83 & 27 & 27 & 0 & 1 & 27 & 0 & $\begin{array}{c}1 \\
\text { among } \\
\text { isolates }\end{array}$ \\
\hline
\end{tabular}

All the isolates were methyl-red (MR) positive, VP negative, indole positive, which are indicative of the identification of E. coli. All the 27 isolates of E. coli showed production of oxygen bubbles indicative for positive result in catalase test. All the isolates of $E$. coli which were presumptively identified on the basis of cultural, Gram's staining and biochemical tests were confirmed by Polymerase chain reaction using genus specific 16SrRNA primers (Figure 1). A total of 27 isolates were confirmed as E. coli by amplifying genus specific 16SrRNA primers. Out of 27 isolates of $E$. coli only one sample was found positive for Stx-2 gene (Table 2, Figure 2). But no samples were found Stx-1 positive. In duplex-PCR, 372 bp sized amplicon of Stx-2 genes were amplified successfully.

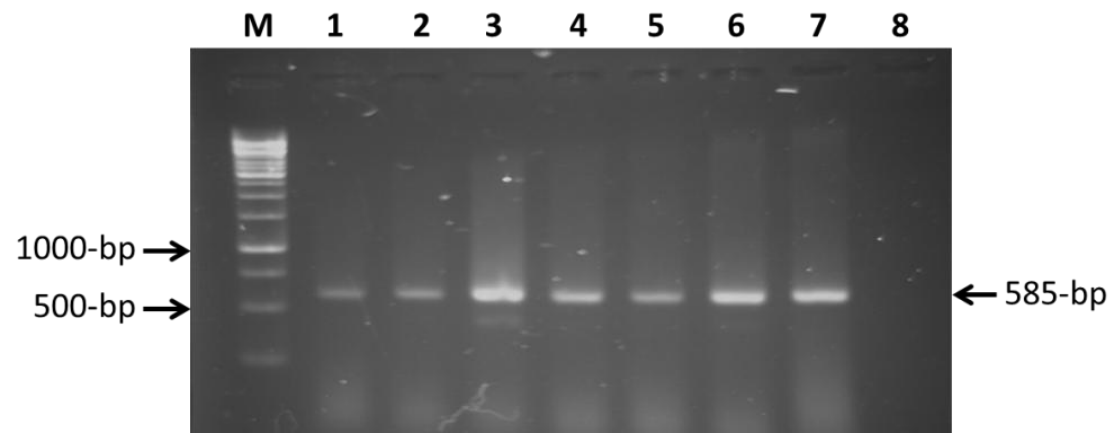

Figure 1. Amplification of 16SrRNA (585 bp) specific genomic primer; Lane 1: $1 \mathrm{kbp}$ DNA ladder, Lane 2-7: positive for 16srRNA; Lane 8: Positive control; Lane 9: Negative control

Out of 83, 27 isolates were found to be positive for 16SrRNA genes. So, overall prevalence of $E$. coli was $32.53 \%$. Among the positive isolates, only 1 isolate (3.70\%) was Stx-2 positive. Overall prevalence of the STEC from the diarrheic children was detected $1.20 \%$. 


\section{M. Islam and others}

All 27 E. coli isolates were tested against 9 antibiotics which are frequently suggested by the pediatricians of the MMCH (Table 3). Among these, Gentamicin showed highest susceptibility (92.59\%), which followed Ciprofloxacin (48.14\%) and Moxifloxacin (33.33\%), respectively (Table 3). Also, Ceftriaxone (29.63\%) and Cefixime $(29.63 \%)$ both were found as moderately sensitive. Highest resistant pattern was showed by Amoxycillin (88.88\%), Azithromycin $(85.18 \%)$, and Cephradine $(85.18 \%)$, followed by Ceftriaxone and Levofloxacin (70.37\%), Cefixime (62.96\%), Ciprofloxacin $(29.62 \%)$ and Gentamicin (7.40\%), respectively (Table 3). More than $77.78 \%$ of the isolates were resistant to at least three or more antibiotics, thus defined as multi-drug resistant (MDR) (Table 4).

This study revealed the prevalence of E. coli was 32.53\%, as supported by Talukdar et al. (2013) who reported the rate as $36 \%$. In our study, on the basis of virulence, the prevalence was $3.70 \%$ of Stx-2 only. Prevalence of Stx-2 among the total samples was $1.20 \%$. This result was inclined with the findings of Islam et al. (2006) who reported that $2.2 \%$ children were infected with STEC. On the other hand, Dhanashree and Mallya (2008) could detect only 1 Stx-2 gene among 140 stool samples. A study in Bangladesh conducted by Albert et al. (1995) showed that STEC was not present in any diarrheic patients in Bangladesh. On the other hand, a study in Calcutta revealed a very low prevalence of STEC among hospitalized patients with diarrhea (i.e., 1.4\% from bloody and $0.6 \%$ from watery stool samples), as reported by Khan et al. (2002). Another study in India also found no STEC in children with diarrhea in Delhi (Bhan et al., 1989). Although slight variation in the prevalence of E. coli in our study was found as compared to some other studies; this variation might be due to difference in the patterns of study, for example, in the cases of those studies, samples were collected from people of different communities, age, sex, food habit and sometimes varying in religion. On the other hand, in our study, samples were collected only from the hospitalized diarrheic children aging between 0-5 years of age.

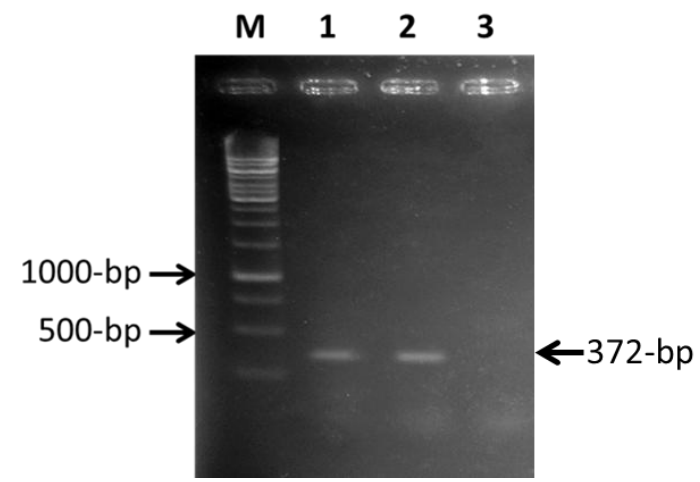

Figure 2. Amplification of Stx-2 (372 bp) genes; Lane 1: $1 \mathrm{kbp}$ DNA ladder, Lane 2: Stx-2 positive gene from E. coli; Lane 3: Positive control; Lane 4: Negative control

Table 3. Antibiogram profile of E. coli isolates

\begin{tabular}{ccccc}
\hline $\begin{array}{l}\text { Antimicrobial agents and } \\
\text { concentration }(\mu \mathrm{g})\end{array}$ & & \multicolumn{3}{c}{ No. of isolates $(\%)$} \\
\cline { 3 - 4 } & & $\mathrm{R}$ & $\mathrm{I}$ & $\mathrm{S}$ \\
\hline Amoxycillin & 30 & $24(88.88)$ & $3(11.11)$ & $0(0.0)$ \\
Azithromycin & 30 & $23(85.18)$ & $4(14.81)$ & $0(0.0)$ \\
Ciprofloxacin & 5 & $8(29.62)$ & $4(14.81)$ & $13(48.14)$ \\
Cefixime & 30 & $17(62.96)$ & $2(7.40)$ & $8(29.63)$ \\
Ceftriaxone & 30 & $19(70.37)$ & $0(0.0)$ & $8(29.63)$ \\
Cephradine & 5 & $23(85.18)$ & $2(25)$ & $4(14.81)$ \\
Gentamicin & 10 & $2(7.40)$ & - & $25(92.59)$ \\
Levofloxacin & 5 & $19(70.37)$ & $0(0.0)$ & $8(29.63)$ \\
Moxifloxacin & 5 & $16(59.25)$ & $2(7.40)$ & $9(33.33)$ \\
\hline
\end{tabular}

*R= Resistant: $\mathrm{I}=$ Intermediate: $\mathrm{S}=$ Sensitive 
Molecular detection and antibiogram of shiga toxin

Table 4. Frequency of distribution of multidrug resistant (MDR) E. coli isolates from collected samples

\begin{tabular}{lc}
\hline Resistance profiles & E. coli \\
No resistance demonstrated & No. of isolates $(\%)$ \\
\hline Resistant to 2 agent (AMX-AZM) & - \\
Resistant to 3 agents & $6(22.23)$ \\
$\bullet \quad$ AMX-AZM-CFM & $1(3.70)$ \\
$\bullet \quad$ AMX-AZM-CH & $1(3.70)$ \\
Resistant to 4 agents & \\
$\bullet \quad$ AMX-AZM-CFM-CIP & $2(7.40)$ \\
$\bullet \quad$ AMX-AZM-CFM-LE & $2(7.40)$ \\
$\bullet \quad$ AMX-AZM-CFM-CH & $2(7.40)$ \\
$\bullet \quad$ AZM-LE-CFM-CTR & $1(3.70)$ \\
Resistant to 5 agents & \\
$\bullet \quad$ AMX-LE-CFM-CH-CTR & $3(11.11)$ \\
$\bullet \quad$ AMX-CIP-CH-GEN-LE & $1(3.70)$ \\
Resistant to 6 agents & \\
$\bullet \quad$ AMX-AZM -LE-CFM-CTR-MOX & $3(11.11)$ \\
$\bullet \quad$ AZM-AMX-GEN-CFM-CTR-CH & $2(7.40)$ \\
$\bullet \quad$ AZM-AMX-GEN-CFM-MOX-CH & $2(7.40)$ \\
Resistant to 7 agents & \\
$\bullet \quad$ AMX-AZM-CFM-CIP-CH-LE-MOX & $1(3.70)$ \\
Total resistant isolates & $27(100)$ \\
\hline
\end{tabular}

Over the last few decades, STEC has been found to be the main cause of diarrheal infection manifested by watery to severe bloody diarrhea in human. Bangladesh is also considered as an important endemic area for diarrheal diseases. Previous report showed that more than 5\% of children aging less than 5 years were attributed to diarrhea every year in Bangladesh (Arifeen et al., 2005). In our study, the prevalence of STEC in children was $1.20 \%$, supported the findings of Arifeen et al. (2005) and Rehman et al. 2014). However, the causes behind the low prevalence of STEC associated diarrhea are not properly understood in Bangladesh (Islam et al., 2006) and India (Khan et al., 2002).

In this study, characteristics colonies of E. coli were observed on EMB agar, MC agar, which was similar to the findings of several previous reports (Nazir et al., 2005; Nazir, 2007; Hassan et al., 2014; Mamun et al., 2016; Tanzin et al., 2016). In Gram's staining method, the isolated bacteria exhibited pink, small rod shaped Gramnegative bacilli. These findings were in support of the findings of Nazir et al. (2005) and Islam et al. (2016).

Stool isolates revealed a complete fermentation of basic sugars as stated by Mckec et al. (1995). E. coli isolates were able to ferment the five basic sugars producing both acid and gas; however, differentiation of $E$. coli into species level was difficult as showed similar reaction in various sugars. All the isolates fermented dextrose, sucrose, fructose, maltose and mannitol with the production of acid and gas within $24 \mathrm{~h}$ of incubation. Results of E. coli isolates were positive as reported by and Mamun et al. (2016). The isolates also revealed positive reaction in MR test and Indole test but negative reaction in V-P test, which was supported by several authors (Nazir et al., 2005; Zinnah et al., 2007; Abbas et al., 2015).

The antibiogram study of all of the 27 isolates against 9 antibiotics used in this study revealed that most of the isolates were MDR. More than $77.78 \%$ of the isolates were found to be resistant to at least three antibiotics. This finding was varied from the findings of Talukdar et al. (2013) who reported the rate as 36\%. This variation might be due to use of old antibiotics in their studies, whereas few newer antibiotics were included in our study. Highest resistant pattern was shown against Amoxycillin (88.88\%), Azithromycin (85.18\%) and Cephradine (85.18\%) followed by Ceftriaxone and Levofloxacin (70.37\%) and Cefixime (62.96\%). Ansari et al. (2014) reported 100\% resistant pattern against Amoxycillin, whereas Islam et al. (2015) and Rehman et al. (2014) reported that $59.15 \%$ and $75 \%$ E. coli were resistant to Amoxycillin. Resistant pattern against Azithromycin $(85.18 \%)$ found in this study was supported by Hossain et al. (2012). 


\section{M. Islam and others}

In our study, highest sensitivity was found against Gentamicin (92.59\%), as reported by Ansari et al. (2014) and Hossain et al. (2012). However Malik et al. (2013) revealed $51.21 \%$ sensitivity to Gentamycin. This variation might be due to extensive use of Gentamycin that caused to emergence of Gentamycin resistant $E$. coli. We also found that Ciprofloxacin was sensitive to $48.14 \%$ samples, which was supported by Dhanashree and Mallya (2008).

From the findings of the study, it may be concluded that, molecular confirmation of $27(32.53 \%)$ isolates of $E$. coli out of 83 samples by PCR using 16SrRNA primer was performed. One isolate $(1.20 \%)$ of E. coli was found as virulent using Stx-1 and Stx-2 primers by molecular technique (duplex-PCR). Gentamicin (92.59\%) and Ciproflxacin $(48.14 \%)$ are the most sensitive against isolated E. coli. So, these antibiotics can be recommended as the effective drugs against STEC infections in children.

\section{REFERENCES}

1. Abbas G, Khan SH, Hassan M, Mahmood S, Naz S and Gilani SS (2015). Incidence of poultry diseases in different seasons in Khushab district, Pakistan. Journal of Advanced Veterinary and Animal Research 2: 141-145.

2. Ahmed MU, Khairuzzaman M, Begum A and Ahmed I (2012). Isolation and antimicrobial susceptibility pattern of Escherichia coli causing urinary tract infection in Enam Medical College Hospital. Journal of Enam Medical College 1: 60-62.

3. Albert MJ, Faruque SM, Faruque ASG, Neogi PKB, Ansaruzzaman M and Bhuiyan NA (1995). Controlled study of Escherichia coli diarrheal infections in Bangladeshi children. Journal of Clinical Microbiology 33: 973-977.

4. Alikhani, Mirsalehian MYA and Aslani MM (2006). Detection of typical and atypicalenteropathogenic Escherichia coli (EPEC) in Iranian children with and without diarrhoea. Journal of Medical Microbiology 55: 1159-1163.

5. Ansari RAIH, Rahman MM, Islam MJ, Das BC, Habib A, Belal SMSH and Islam K (2014). Prevalence and antimicrobial resistance profile of Escherichia Coli and Salmonella isolated from diarrheic calves. Journal of Animal Health and Production 2: 12-15.

6. Arifeen SE, Akhter T, Chowdhury HR, Rahman KM and Chowdhury EK (2005). Causes of death in children under five years of age. In National Institute of Population Research and Training, Bangladesh Demographic and Health Survey 2004. Dhaka, Bangladesh and Calverton MD: National Institute of Population Research and Training (NIPORT), Mitra and Associates, and ORC Macro. pp. 125-133.

7. Bauer AW, Kirby WMM, Sherris JC and Turck M (1966). Antibiotic susceptibility testing by a standardized single disc method. American Journal of Clinical Pathology 45: 493-496.

8. Bhan M, Raj P, Levine MM, Kaper J B, Bhandari N and Srivastava R (1999). Enteroaggregative Escherichia coli associated with persistent diarrhea in a cohort of rural children in India. Journal of Infectious Diseases 159: 10611064.

9. CLSI (2013). Clinical and Laboratory Standards Institute (CLSI) guidelines. 27: Wane, PA, USA.

10. Dhanashree B and Mallya PS (2008). Detection of shiga-toxigenic Escherichia coli (STEC) in diarrhoeagenic stool \& meat samples in Mangalore, India. Indian Journal of Medical Research 128: 271.

11. Hassan J, Parvej MS, Rahman MB, Khan MS, Rahman MT, Kamal T and Nazir KHMNH (2014). Prevalence and characterization of Escherichia coli from rectal swab of apparently healthy cattle in Mymensingh, Bangladesh. Microbes and Health 3: 12-14.

12. Heuvelink AE, van de Kar NC, Meis JF, Monnens LA and Melchers WJ (1995). Characterization of verocytotoxinproducing Escherichia coli $\mathrm{O} 157$ isolates from patients with haemolytic uraemic syndrome in Western Europe. Epidemiology and Infection 115: 1-14.

13. Higgins JA, Belt KT, Karns JS, Russell-Anelli J and Shelton DR (2005). tir-and stx-positive Escherichia coli in stream waters in a metropolitan area. Applied and Environmental Microbiology 71: 2511-2519.

14. Hossain MK, Rahman M, Nahar A, Khair A and Alam MM (2012). Isolation and identification of diarrheagenic Escherichia coli causing colibacillosis in calf in selective areas of Bangladesh. Bangladesh Journal of Veterinary Medicine 11: 145-149.

15. Islam AKMA, Rahman M, Nahar A, Khair A and Alam MM (2015). Investigation of pathogenic Escherichia coli from diarrheic calves in selective area of Bangladesh. Bangadesh Journal of Veterinary Medicine 13: 45-51

16. Islam K, Ahad A, Barua M, Islam A, Chakma S, Dorji C, Uddin MA, Shariful Islam and Ahasan ASML (2016). Isolation and epidemiology of multidrug resistant Escherichia coli from goats in Cox's Bazar, Bangladesh. Journal of Advanced Veterinary and Animal Research 3: 166-172. 
17. Islam MA, Heuvelink AE, E de Boer, Sturm PD, Beumer RR, Zwietering MH, Manna SK, Brahmane MP, Manna C, Batabyal K and Das R (2006). Occurrence, virulence characteristics and antimicrobial resistance of Escherichia coli $\mathrm{O} 157$ in slaughtered cattle and diarrheic calves in West Bengal, India. Letters in Applied Microbiology 43: 405-409.

18. Islam MB, Yusuf MA, Chowdhury MS, Sattar AA and Afrin S (2015). Frequency and Distribution of Gram Negative Bacteria among Hospital and Community Acquired UTI Patients. Bangladesh Journal of Infectious Diseases 1: 24-26.

19. Jahan F, Mahbub-E-Elahi AT and Siddique AB (2016). Bacteriological Quality Assessment of Raw Beef Sold in Sylhet Sadar. The Agriculturists 13: 9-16.

20. Kaddu-Mulindw DH, Aisu T, Gleier K, Zimmermann S and Beutin L (2001). Occurrence of shiga toxin-producing Escherichia coli in fecal samples from children with diarrhea and from healthy zebu cattle in Uganda. International Journal of Food Microbiology 66: 95-101.

21. Khan A, Yamasaki S, Sato T, Ramamurthy T, Pal A, Datta S, Chowdhury NR, Das SC, Sikdar A, Tsukamoto T, Bhattacharya SK, Takeda Y and Nair GB (2002). Prevalence and genetic profiling of virulence determinants of non-0157 Shiga toxin-producing E. coli isolated from cattle, beef and humans, Calcutta, India. Emerging Infectious Diseases 8: 54-62.

22. Leelaporn A, Phengmak M, Eampoklap B, Manatsathit S, Tritilanunt S, Siritantikorn S, Nagayama K, Iida T, Niyasom C and Komolpit P (2003). Shigatoxin- and enterotoxin-producing Escherichia coli isolated from subjects with bloody and non-bloody diarrhea in Bangkok, Thailand. Diagnostic Microbiology and Infectious Disease 46: 173-180.

23. Malik S, Kumar A, Verma AK, Gupta MK, Sharma SD, Sharma AK and Rahal A (2013). Haematological profile and blood chemistry in diarrhoeic calves affected with colibacillosis. Journal of Animal Health and Production 1: $10-14$.

24. Mamun MM, Parvej MS, Ahamed S, Hassan J, Nazir KHMNH, Nishikawa Y and Rahman MT (2016). Prevalence and characterization of shigatoxigenic Escherichia coli in broiler birds in Mymensingh. Bangladesh Journal of Veterinary Medicine 14: 5-8.

25. McKec IA, Melton CA, Moxley RA, Fancis DH and Brien OAD (1995). Enterohemorrhaic E. coli 0157:H7 requires initimin to colonize the genotobiotic pig intestine and to adhere to HEP-2 cells. Infection and Immunology 63: 3739-3744.

26. Munshi SK, Rahman MM and Noor R (2012). Detection of virulence potential of diarrhoeagenic Escherichia coli isolated from surface water of rivers surrounding Dhaka city. Journal of Bangladesh Academy of Sciences 36: 109121.

27. Nazir KHMNH (2007). Plasmid profiles and antibiogram pattern of Escherichia coli isolates of calves feces and diarrhegenic stool of infants. Journal of the Bangladesh Society of Agricultural Science and Technology 4: 149152.

28. Rehman MU, Rashid M, Sheikh JA and Bhat MA (2014). Molecular epidemiology and antibiotic resistance pattern of Enteropathogenic Escherichia coli isolated from bovines and their handlers in Jammu, India. Journal of Advanced Veterinary and Animal Research 1: 177-181.

29. Schippa S, Iebba V, Barbato M, Di Nardo G, Totino V, Checchi MP, Longhi C, Maiella G, Cucchiara S and Conte MP (2010). A distinctive'microbial signature'in celiac pediatric patients. BMC Microbiology Journal 10: 1.

30. Talukdar PK, Rahman M, Rahman M, Nabi A, Islam Z, Hoque MM, Endtz HP and Islam MA (2013). Antimicrobial resistance, virulence factors and genetic diversity of Escherichia coli isolates from household water supply in Dhaka, Bangladesh. PloS One 8: 610-690.

31. Tanzin T, Nazir KHMNH, Zahan MN, Parvej MS, Zesmin K and Rahman MT (2016). Antibiotic resistance profile of bacteria isolated from raw milk samples of cattle and buffaloes. Journal of Advanced Veterinary and Animal Research 3: 62-67.

32. Turner SM, Scott-Tucker A, Cooper LM and Henderson IR (2006). Weapons of mass destruction: virulence factors of the global killer enterotoxigenic Escherichia coli. FEMS Microbiology Letters 26: 310-20.

33. Zinnah MA, Bari MR, Islam MT, Hossain MT, Rahman MT, Haque MH, Babu SAM, Ruma RP and Islam MA (2007). Characterization of Escherichia coli isolated from samples of different biological and environmental sources. Bangladesh Journal of Veterinary Medicine 5: 25-32. 